\title{
The Effect of Nickel Plating on the Fatigue Strength of
}

\section{Carbon Steel ${ }^{*}$}

\author{
By Hisakichi SUNADA**
}

\section{Synopsis}

The electro-plating to metallic material makes the fatigue strength decrease. The mechanism of the decrease of fatigue strength by plating was investigated by alternately stressing nickel plated carbon steels. The test data suggest that the decrease of fatigue strength is related to fatigue crack in plated layer.

It is believed that this decrease of fatigue limit is caused by the embrittlement resulting from the occlusion of hydrogen and the interaction of internal stresses.

\section{Introduction}

The engineering application of electro-plating is wide; for example, to beautify the appearance of machine parts, to increase the surface hardness and promote the wear resistance, and to improve the corrosion resistance. When alternately stressed, however, the fatigue strength of electro-plated parts decreases markedly. Therefore, methods of overcoming this trouble are today being demanded.

Although the effect of chromium plating on the fatigue strength has been investigated by Wiegand et al., ${ }^{1)}$ only a few informations are availabe for the nickel plating. ${ }^{2)}$ It is by this reason that an attempt was made by this author to give a systematic study for the problem in the nickel plating.

The results of investigation described in this paper comprise two facets of the problem: the effect of plating condition on the fatigue strength, and the effect of baking on the fatigue strength.

\section{Experimental Method}

Chemical compositions of the steels used in this investigation are given in Table 1. After as-received materials were rough machined, steels S10C and S15C were annealed at $910^{\circ} \mathrm{C}$ only, and steels S40C and S45C were annealed at $830^{\circ} \mathrm{C}$, or quenched at $830^{\circ} \mathrm{C}$ and tempered at $550^{\circ} \mathrm{C}$. Annealing is denoted by " $A$ ", and quenching plus tempering by "QT". Then the specimens were finished by grinding as shown in Fig. 1. In Table 2 the properties of steels are summarized.

The nickel plating solution used consisted of $240 \mathrm{~g} / \mathrm{l}$

Table 1. Chemical composition of specimen

\begin{tabular}{c|c|c|c|c|c|c}
\hline & $\mathrm{C}$ & $\mathrm{Si}$ & $\mathrm{Mn}$ & $\mathrm{P}$ & $\mathrm{S}$ & Note \\
\cline { 1 - 6 } $\mathrm{S} 15 \mathrm{C}$ & 0.15 & 0.25 & 0.51 & 0.014 & 0.027 & As-plated \\
$\mathrm{S} 10 \mathrm{C}$ & 0.10 & 0.25 & 0.50 & 0.015 & 0.020 & As-baked \\
\hline $\mathrm{S} 45 \mathrm{C}$ & 0.44 & 0.26 & 0.77 & 0.027 & 0.024 & As-plated \\
$\mathrm{S} 40 \mathrm{C}$ & 0.41 & 0.29 & 0.69 & 0.018 & 0.022 & As-baked
\end{tabular}

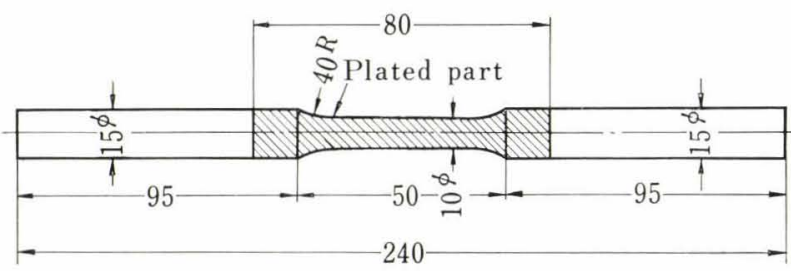

Fig. 1. Fatigue test specimen

Table 2. Mechanical properties of specimen

\begin{tabular}{l|c|c|c|c|c} 
& $\begin{array}{c}\text { Yield } \\
\text { strength } \\
\left(\mathrm{kg} / \mathrm{mm}^{2}\right)\end{array}$ & $\begin{array}{c}\text { Tensile } \\
\text { strength } \\
\left(\mathrm{kg} / \mathrm{mm}^{2}\right)\end{array}$ & $\begin{array}{c}\text { Elonga- } \\
\text { tion } \\
(\%)\end{array}$ & $\begin{array}{c}\text { Hard- } \\
\text { ness } \\
\left(H_{V}\right)\end{array}$ & Note \\
\hline $\mathrm{S} 15 \mathrm{C} \cdot A$ & 27.6 & 42.5 & 37.8 & 128 & As-plated \\
$\mathrm{S} 10 \mathrm{C} \cdot A$ & 33.4 & 41.0 & 43.3 & 123 & As-baked \\
\hline $\mathrm{S} 45 \mathrm{C} \cdot A$ & 35.4 & 62.6 & 27.2 & 165 & As-plated \\
$\mathrm{S} 40 \mathrm{C} \cdot A$ & 34.2 & 57.6 & 28.5 & 178 & As-baked \\
\hline $\mathrm{S} 45 \mathrm{C} \cdot Q T$ & 88.6 & 95.6 & 18.8 & 316 & As-plated \\
$\mathrm{S} 40 \mathrm{C} \cdot Q T$ & 62.7 & 82.2 & 23.5 & 308 & As-baked
\end{tabular}

$\mathrm{NiSO}_{4} \cdot 7 \mathrm{H}_{2} \mathrm{O}, 45 \mathrm{~g} / l \mathrm{NiCl}_{2} \cdot 6 \mathrm{H}_{2} \mathrm{O}$, and $30 \mathrm{~g} / l \mathrm{H}_{3} \mathrm{BO}_{3}$, and plating was operated generally under a current density of $1 \mathrm{~A} / \mathrm{dm}^{2}$ and the bath temperature of $25^{\circ} \mathrm{C}$. The control of thickness of plating was carried out by the current density and the duration in the plating operation. The thickness of plating was measured with a micrometer.

After nickel plating, the specimens were rinsed and dried, and baked at temperatures between $20^{\circ}$ to $550^{\circ} \mathrm{C}$ for $2 \mathrm{hr}$ in air.

The fatigue tests were conducted in air by Ono's rotating beam fatigue test machine, applying 1750 reversals of stress $/ \mathrm{min}$. In all the test, the stresses were calculated on the diameter of specimen prior to plating.

\section{Test Results}

$\mathrm{S}-\mathrm{N}$ curves for nickel plated steels are given in Fig. 2 for various plating conditions, i.e. the fatigue strength of nickel plated steels, as a function of the current density, and the thickness of plating.

S-N curves for nickel plated steels baked at various temperatures after plating are given in Fig. 3.

The relation between the fatigue limit of not-plated steel and that of plated steel (the plating condition: current density $1 \mathrm{~A} / \mathrm{dm}^{2}$; thickness approx. $0.09 \mathrm{~mm}$ ) is shown in Fig. 4. These curves demonstrate that nickel plating decreases the fatigue limit and the

* Originally published in J. Soc. Materials Science, Japan, 15 (1966), 230; 16 (1967), 865. English version received September 4, 1968.

** Department of Metallurgy, Himeji Institute of Technology, Idei, Himeji 600. 

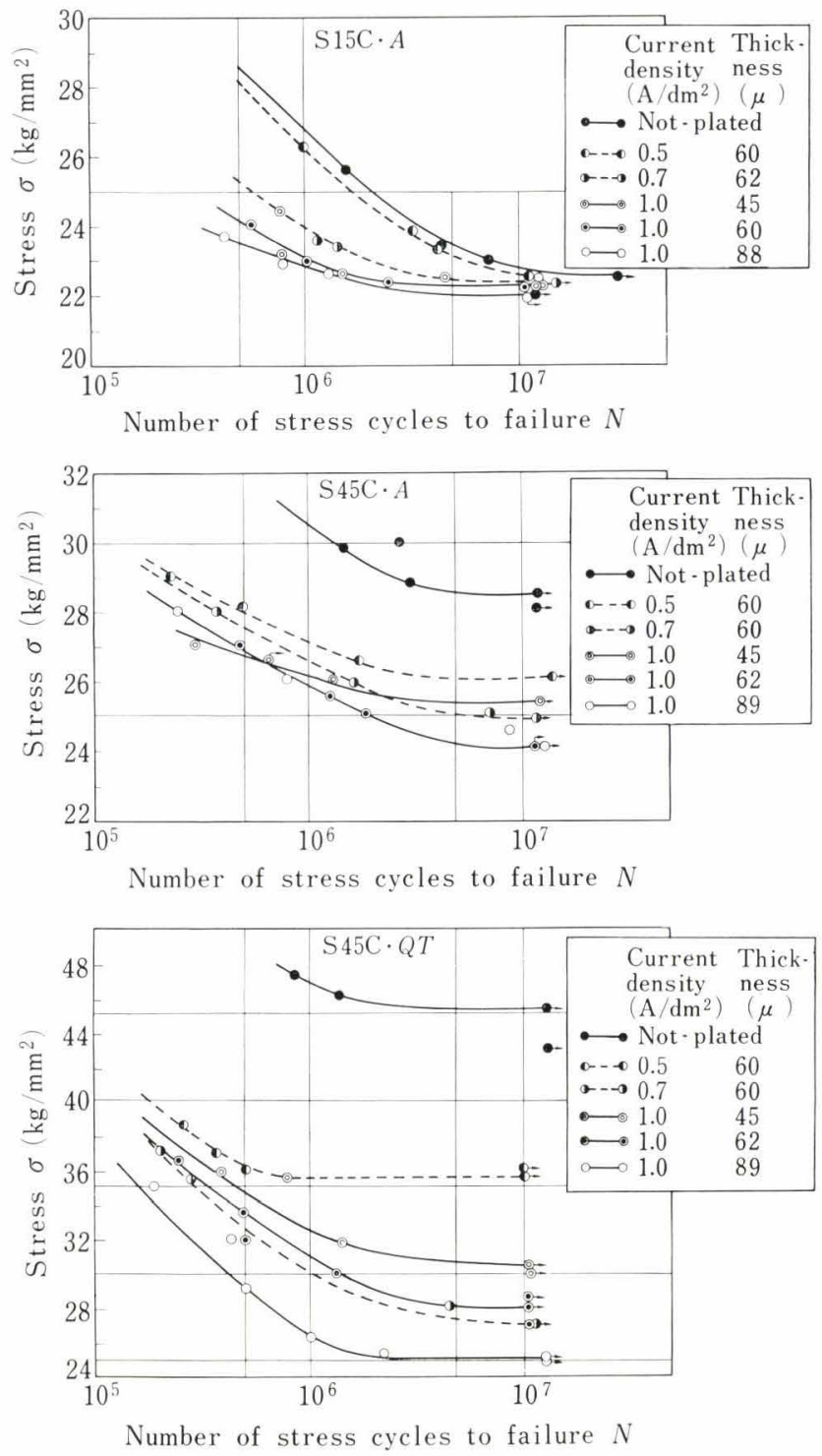

Fig. 2. $\mathrm{S}-\mathrm{N}$ curves for various plating conditions

decrease in fatigue limit increases progressively with increasing strength of not-plated steel.

The effect of current density on fatigue limit is shown in Fig. 5. Fatigue limit of plated steel decreases with increasing current density. The effect is more pronounced on quenched-and-tempered steel than on annealed steel.

The fatigue limit of steels that are plated to various thicknesses (at current density of $1 \mathrm{~A} / \mathrm{dm}^{2}$ ) is shown in Fig. 6. The decrease of the fatigue limit resulting from plating increases with increasing thickness. The extent of decrease in S45C QT steel is the largest of these steels. The difference between the fatigue limit of $\mathrm{S} 45 \mathrm{C} Q T$ steel and that of $\mathrm{S} 15 \mathrm{C} A$ steel diminishes with increasing thickness of plating.

It may be concluded from the test data obtained that the extent of decrease of fatigue limit depends upon the strength of steel, the current density, and the thickness of plating. Explanations that have been advanced for the fact that the fatigue limit of steels is reduced by nickel plating are: (1) the embrittlement due to hydrogen, or (2) the presence of internal stress in nickel
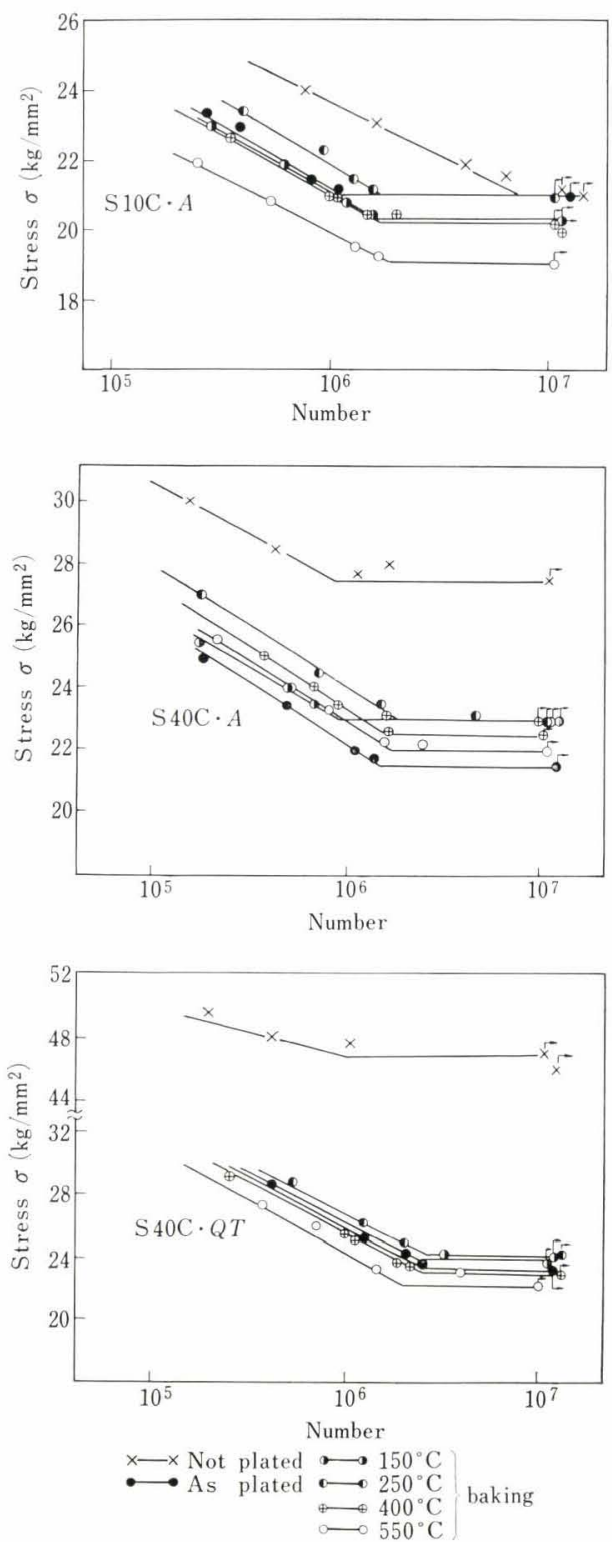

Fig. 3. Effect of baking on $\mathrm{S}-\mathrm{N}$ curves of Ni-plated steel

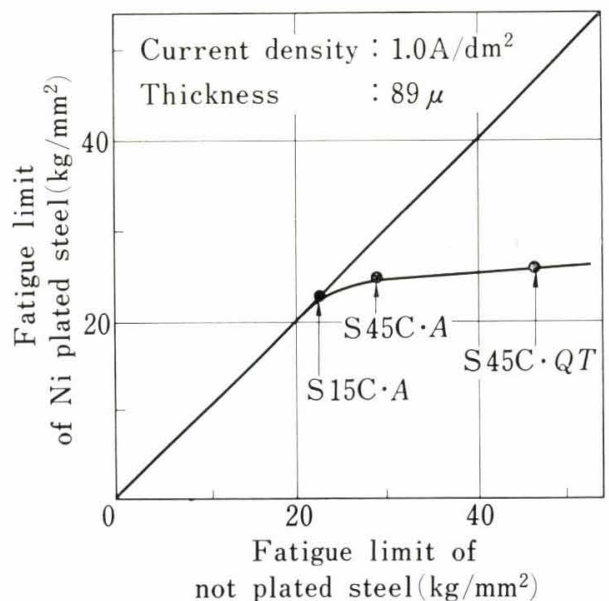

Fig. 4. Relation between fatigue limits of Ni-plated and notplated steel

plated layer. ${ }^{3)}$ If the decrease in fatigue limit of nickel plated steel were to be attributed to those causes, the reduced fatigue limit should be recovered by re- 
moval of hydrogen and the relief of internal stress, and this should be achieved in the baking after plating.

Figure 7 summarizes the effect of baking after plating on fatigue limit from Fig. 3. As mentioned above, fatigue limit of as-nickel plated specimen decreases by plating. This decrease of fatigue limit recovers slightly by baking at $250^{\circ} \mathrm{C}$. By baking at temperatures above $250^{\circ} \mathrm{C}$, however, the fatigue limit becomes lower until at $550^{\circ} \mathrm{C}$ when it becomes lower than that of the unbaked plated steel.

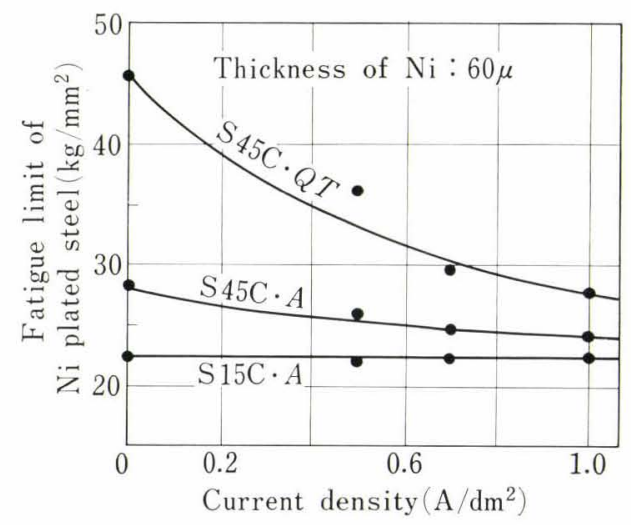

Fig. 5. Relation between fatigue limit of Ni-plated steel and current density of plating

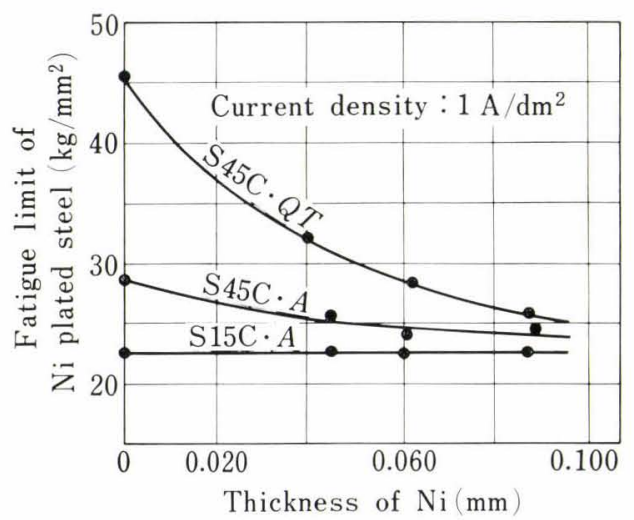

Fig. 6. Relation between fatigue limit of Ni-plated steel and thickness of $\mathrm{Ni}$

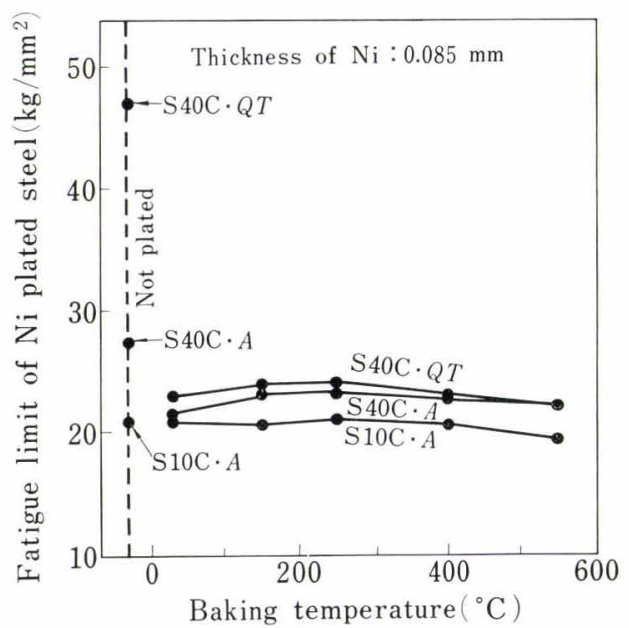

Fig. 7. Relation between fatigue limit and baking temperature
An inference from these data is that the recovery of the fatigue limit by baking is little; baking after plating is not expected to recover the decrease of fatigue limit by plating. The decrease of fatigue limit by plating is not, at least in major part, caused by internal stress or occluded hydrogen.

The residual stress existing in nickel plated layer was measured by strain gauge method with sheet specimen of dimension $150 \times 20 \times 0.25 \mathrm{~mm}$, one side of which was exposed for nickel plating. The dependence of internal stress on current density at thickness of $0.06 \mathrm{~mm}$ is plotted in Fig. 8, which increases with current density. It was found that the nickel plated layer does contain a residual tensile stress, which increases with current density.

Figure 9 shows the change of the hardness of steel and the nickel plated layer by heating.

The microstructure of cross section of plated layer after baking is shown in Photo. 1. The structure of as-plated layer is columnar; numerous fine grains appear as the temperature of baking increases. Softening of nickel plated layer may be due to the change of structure of plated layer by heating.

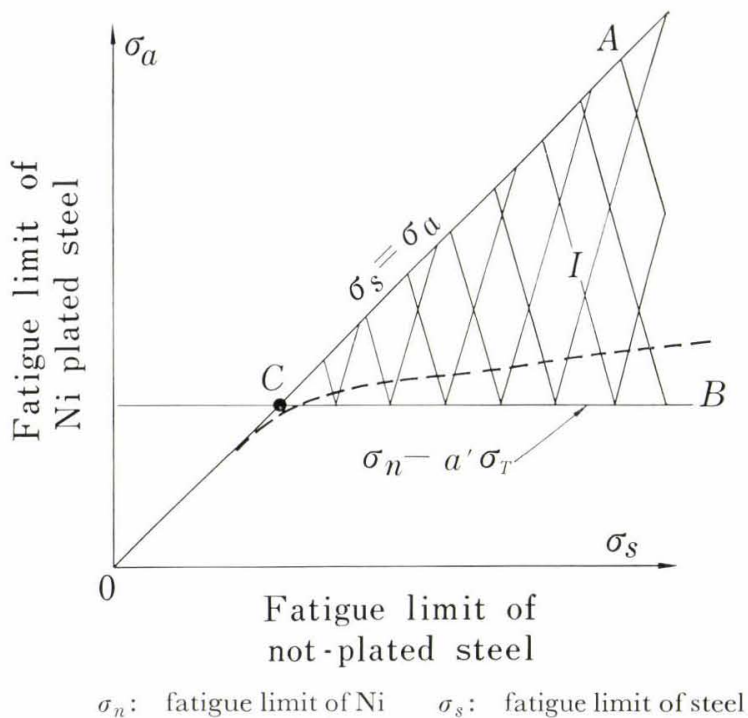

Fig. 8. Schematic relation between fatigue limit of $\mathrm{Ni}$ plated and not-plated steel

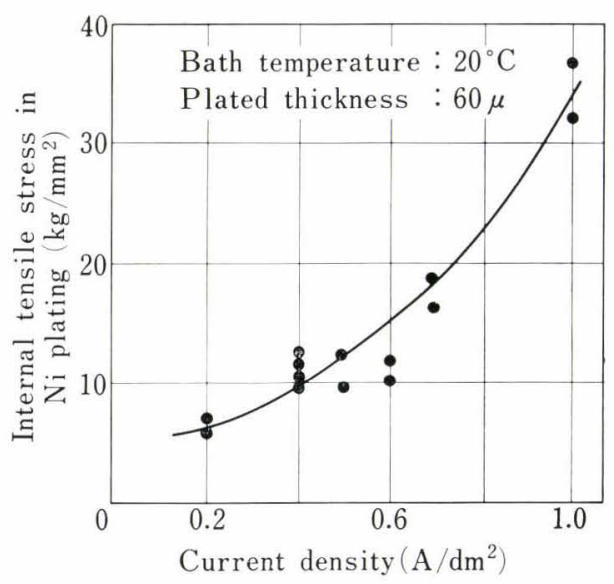

Fig. 9. Relation between internal stress and current density 


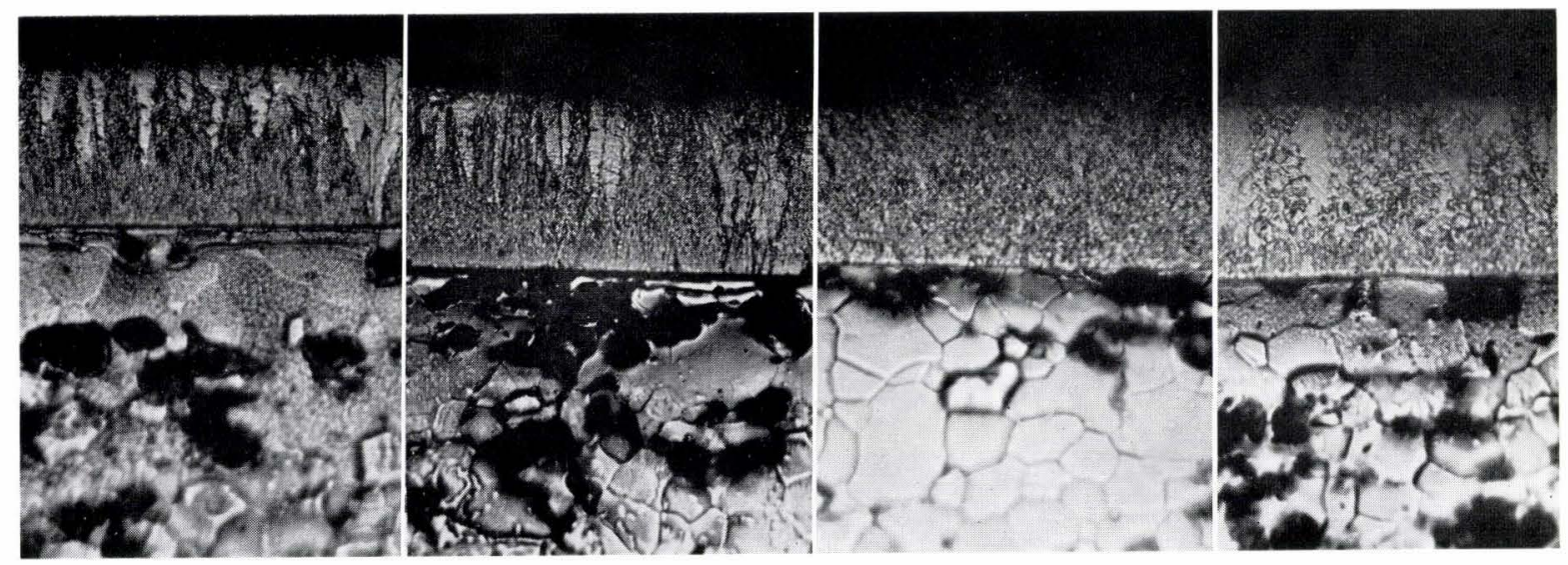

Photo. 1. Microstructures of nickel plated layer $(\times 200)(1)$

\section{Discussion}

The reason for the fact that fatigue limit of steel is reduced by nickel plating has been believed to be found most likely in (1) the embrittlement due to occluded hydrogen and (2) the presence of internal stress in plated layer. ${ }^{3)}$ The weakness of those theories is that they were put forward without substantiation. The mechanism that controls the decrease of fatigue strength by plating has not been systematically studied.

Assume that a specimen (diameter before plating $d_{o}$, diameter after plating $d_{p}$ ) subjected to repeating bending stress $\sigma_{a}$, will fail, when the stress exceeds the intrinsic fatigue limit of the material. The residual tensile stress that is generally present in the plated layer $\sigma_{T}$ acts as the mean stress in the fatigue test; it is evaluated as an alternating stress with the aid of an equivalency constant $\alpha$, i.e. as $\alpha \sigma_{T}$. Also in the base steel, a compression stress $\alpha^{\prime} \sigma_{c}$ acts to balance this stress.

The condition of fatigue fracture that the fatigue crack starts at the surface under this combined stress $\left(\sigma_{a}+\alpha \sigma_{T}\right)$ acting in the plated layer is then the simultaneous fulfillment of following two conditions:

(1) the tensile stress $\left(\sigma_{a}+\alpha \sigma_{T}\right)$ acting on the surface be greater than the fatigue limit of plated metal $\sigma_{n}$, and

(2) the stress acting at boundary between the plated layer and the steel $\left(d / d_{p}\right) \sigma_{a}-\alpha^{\prime} \sigma_{c}$ be smaller than the fatigue limit of the steel $\sigma_{s}$.

These conditions can be expressed by inequality equations:

$$
\left.\begin{array}{l}
\alpha \sigma_{T}+\sigma_{a}>\sigma_{n} \\
\left(d / d_{p}\right) \sigma_{a}-\alpha^{\prime} \sigma_{c}<\sigma_{s}
\end{array}\right\}
$$

When $\beta$ is the ratio of compressive stress $\sigma_{c}$ to tensile stress $\sigma_{T}$, it may be written as

$$
\beta=\frac{\sigma_{c}}{\sigma_{T}}=\frac{d_{p}^{2}-d^{2}}{d^{2}}=\left(\frac{d_{p}}{d}\right)^{2}-1>0
$$

When the plated layer is thin, i.e. $(d p / d) \cong 1, \beta$ will approach to 0 . Equations (1) can then be rewritten as

$$
\sigma_{n}-\alpha \sigma_{T}<\sigma_{a}<\sigma_{s}
$$

Equation (2) is indicated in Fig. 10. In this figure, the domain $I$ shows that the fatigue limit decreases with

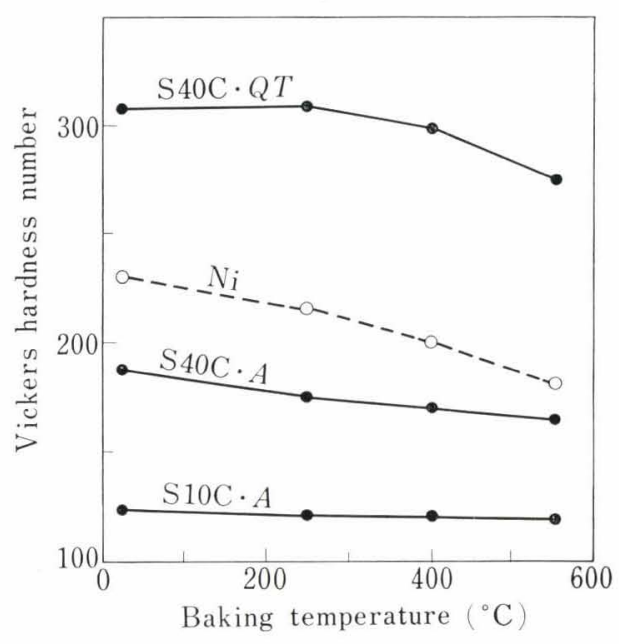

Fig. 10. Relation between hardness and baking temperature

the residual tensile stress in plated layer. Further, it becomes larger with increasing strength of steel as actually observed; the dotted line shows the test data from Fig. 4. It is now possible to explain the reason for the influence of residual stress on the decrease of fatigue limit of nickel plated carbon steel.

If the residual stress in plated layer can be ignored, the fatigue limit of the plated metal $\sigma_{n}$ will become smaller that much. In this case a fatigue crack can be easily initiated on the surface. When a crack begins to appear in the plated layer and propagates into the steel, the crack will exert a notch effect, corresponding to its depth, on the surface of the substrate steel.

Generally the greater the value of stress concentration factor, the harder the steel. It may then be that the decrease of fatigue limit by plating is larger, when the harder the steel and the thicker the platings; for the same fatigue limit, stress concentration by plating will become greater as the thickness increases. Thus the decrease in fatigue strength increases with the thickness of plating.

The residual stress existing in nickel plated layer was measured by strain gauge method with sheet specimen of dimension $150 \times 20 \times 0.25 \mathrm{~mm}$, one side of which was exposed for nickel plating. It was found that the 
nickel plated layer does contain a residual tensile stress, which increases with current density. The dependence of internal stress on current density at thickness of $0.06 \mathrm{~mm}$ is plotted in Fig. 9 .

The reason for the lowering in fatigue strength as the result of nickel plating is attributed to internal stress and a crack in plated layer, ignoring the influence of occluded hydrogen, in the above discussion. Hence baking after plating have been studied to ensure the influence of hydrogen and internal stress on the fatigue limit of nickel plated steel. It is convenient to classify the effect of baking after nickel plating as due to:

(1) the weakening of the substrated steel,

(2) the relief of the stress in plated layer,

(3) the removal of the occluded hydrogen.

The nickel plated layer becomes progressively softer with elevation of the baking temperature. The harder the layer of nickel plating, the higher will the residual tensile stress be, therefore, the residual stress should have been more relieved by baking as the hardness of nickel plated layer decreased. ${ }^{4)}$ On the other hand, baking up to $550^{\circ} \mathrm{C}$ tends to decrease the hardness, hence the fatigue limit, of steel. Combining the changing hardness of nickel and steel, the following conclusion may be derived.

Baking at a temperature range from $150^{\circ}$ to $250^{\circ} \mathrm{C}$ relieves the residual stress and the decrease of the fatigue limit in the plated steel is recovered. Above $250^{\circ} \mathrm{C}$, both the fatigue limit of steel and the residual stress decrease. In baking at $550^{\circ} \mathrm{C}$ the fatigue limit of plated specimen decreases to that prior to baking.

As the occluded hydrogen is said to be removed by heating at $200^{\circ} \mathrm{C},{ }^{5}$ ) the improvement of fatigue limit by baking at $250^{\circ} \mathrm{C}$ seems to be due to this phenomenon. But its effect is not significant.

It is tentatively concluded from those results that the main factor controlling the fatigue strength of nickel plated steel is neither the embrittlement due to hydrogen nor the presence of internal stress, but the crack produced by fatigue in the nickel plated layer.

\section{Conclusions}

The fatigue test specimens used in the present investigation were $10 \mathrm{~mm}$ in diameter, and were made of annealed approximate $0.1 \% \mathrm{C}$ steel, annealed and quenched tempered approximate $0.4 \mathrm{C}$ steel. The nickel plating of fatigue test specimens were carried out in the standard Watts' type bath. The fatigue test was conducted under rotatory bending stressing. The results obtained can be summarized as follows:

(1) The higher the fatigue limit of the unplated steel, the lower the limit of the nickel plated steel irrespective of the plating condition.

(2) The higher the plating current density, the larger the decrease of the fatigue limit of nickel plated steel.

(3) Moreover the decrease of the fatigue limit of the nickel plated steel is influenced by the thickness of plating.

(4) By baking up to $250^{\circ} \mathrm{C}$, the fatigue limit of nickel plated steel increases slightly with decreasing hardness of the nickel plated layer. Baking above $550^{\circ} \mathrm{C}$, however, causes the fatigue limit to become lower than that before baking.

\section{REFERENCES}

1) H. Wiegand and H. R. Kaiser: Metalöberflacke, 18 (1964), 225, 257, 289, 325.

2) C. Williams and R. A. F. Hammond: Trans. Inst. Metal Finishing, 34 (1957), 314.

3) M. Kawamoto and Y. Mizukami: J.S.M.S., 3 (1954), 427.

4) S. Konishi: J. Metal Finishing (Japan), 12 (1961), 47.

5) L. S. Darken and R. S. Smith: Corrosion, 5 (1949), 1. 